\title{
Respecting sameness and difference: taking account of gender in research on smoking
}

- $\quad$ I first began to think about the issues raised in the paper

- by Clarke and colleagues, published in this issue of Tobacco Control, pages 201-208, in 1982, and my attention then was focused on women. Most of the research on attitudes and behaviour seemed to have been carried out on men before then, with no regard for women's experience, with one exception that I recall. ${ }^{1}$ At that time, there were several untested hypotheses: that women were less likely to stop smoking than men, were likely to find it more difficult to stop, possibly because women may have greater reliance on smoking for controlling negative affect, and were also more liable to relapse, possibly for the same mood-controlling reasons. This created a picture of women as more likely to be victims of cigarette smoking addiction.

The power of these untested hypotheses, seen most often in the media, provided me and others with questions and ideas for research which we are still attempting to answer. The paper by Clarke and colleagues in this issue raises further questions of great importance to the field.

What Clarke and colleagues are saying is that, with a large representative research population, asking questions about smoking which are embedded in a much larger survey of attitudes and beliefs means we are more likely to get at the truth of women's and men's attitudes and beliefs about smoking than we are through research which focuses on smoking alone. This must be true and, I believe, gives us a view of what it is about attitudes to smoking that men and women have in common, and what they don't. Clarke et al are also arguing for gender-neutral treatment of smoking prevention and cessation because, from their analysis, gender does not explain attitudinal variables, but smoking does and so do gender-related social experiences.

The matrix of gender, social role and smoking behaviour categories put forward by this research team has a satisfying explanatory power for our understanding of the levelling of smoking prevalence and attitudes towards smoking found in this large survey. Nevertheless, I found myself with a strong internal "Yes, but..." when I read the paper, and the rest of what I have to say is my attempt to put this feeling into words.

What remains unanswered for me, from this analysis, is the extent to which it explains motivations to smoke for women and for men, and whether these motivations may function on a rational level which is different for men and women, because of their differing social experiences. For example, what many women who smoke clearly fear is the prospect of weight gain on stopping smoking. This analysis demonstrates this apprehension, and the US Surgeon General's report ${ }^{2}$ confirms women's fears, in that most people do seem to gain at least a little weight when stopping smoking. On the other hand, a survey of UK smoking attitudes and behaviour showed that only $6 \%$ of ex-smokers were likely to mention weight gain following cessation as a problem. ${ }^{3}$

Clarke and colleagues suggest that more publicity needs to be given to the fact that fears of weight gain are "relatively unlikely to be realised by the majority of female ex-smokers". Grunberg and colleagues ${ }^{4}$ make a similar claim: "... the average weight gain after smoking cessation is only $5 \mathrm{lb}$ (USDHHS, 1990). Perhaps exaggerated perceptions need to be corrected." From my experience of working with women who smoke, and from observing developments in research and health promotion messages, there seems to be a tension between the fears that women have about weight gain and the professionals' view that the prospect of gaining 5-7 lbs is not a life-threatening issue. That tension between the two views arises from women feeling unheard, and professionals also feeling unheard. So the solution currently being proposed is that we write the messages in bigger letters and say it loud to women: YOU WON'T GAIN MUCH WEIGHT WHEN YOU STOP SMOKING!

This general trend dismisses women's experience. For many women, putting on 5 lbs may be unthinkable: it may necessitate an increase in clothes' size, which many women would not be prepared to contemplate. I remember a dancer who walked out of a stop-smoking group because I could not guarantee she would not put on weight. What intrigues and saddens me is the obvious conclusion that some women would rather die sooner of smoking than put on weight. It is easy to say that media stereotypes of thin women, and many men's avowed preference for slim women, are what determine this state of affairs. I would like to suggest that there is another aspect to this issue, which may give greater explanatory power to women's fears of weight gain, and this is related to affect control.

Interlinked with the appetite suppression reward for smoking is the negative affect control often required by women from smoking. This aspect of tobacco use would benefit from further exploration. Could it be, for instance, that women who are suppressing negative mood states with cigarettes know that cessation will lead to them suppressing negative mood states with food and/or alcohol? If so, a clear choice is being made and the perceived benefits of continued cigarette smoking are that women stay functional in their social roles (which alcohol would disallow), they stay "cool" by suppressing their anger or anxiety (expression of which evokes social disapproval) and they stay underweight (which evokes self and social approval). Greaves ${ }^{5}$ remarks: "Only in revealing such benefits can we attempt to change attitudes, and raise awareness amongst girls and women, not simply about the health risks of smoking, but also about the considerable social and economic exploitations attached to women's smoking".

Waldron, in her comprehensive review of gender differences in smoking, ${ }^{6}$ concludes: “... even for groups in which there is little or no gender difference in the prevalence of smoking, there may be important gender differences in the factors that motivate smoking" and that "... programs to prevent smoking adoption and to promote smoking cessation may be more effective if these programs take into account gender differences in the factors that influence smoking adoption and cessation".

To be fair, Clarke and colleagues go on to say that "counselling on weight control strategies and exercise should be a part of smoking cessation programmes and materials." This is a necessary, and not sufficient, component of providing help for people in the process of giving up smoking. If such strategies are used in isolation 
from the awareness-raising at a social level proposed by Lorraine Greaves, then we continue to preach self-control to women, instead of self-understanding.

Research in the UK and in Canada has helped to give more understanding of the meaning of smoking to women. ${ }^{5,7,8}$ There appears to be a consensus that those women in the most deprived circumstances are most likely to say they need to smoke, that smoking is an essential part of their coping mechanism. My own feeling, from having worked with two distinct research populations, ${ }^{9,10}$ is that women who feel powerless, whether through social deprivation or through frustration with lack of support at work or the "glass ceiling" on access to senior management positions, are more likely to use smoking as a signal of their discontent. I feel that claims that women want to smoke like men, so as to be like men, are wrongfooted somehow. The last decades of progress in women's social roles have led to a greater awareness of the limitations placed upon them by men, that their access to power in western society is blocked, or grudgingly given, and from these recognitions the smoke signals arise.

Clarke et al suggest that, at present, social role (especially occupational) category and smoking category are more indicative of attitudes to smoking than is gender category, and that the impact of these may change over time or in different contexts. So, for example, a UK female consultant gynaecologist who smoked in 1953 would have been remarkable for her gender in relation to her occupational category; and in 1993 she would be remarkable for her smoking behaviour in relation to her occupational category. Social role boundaries are constantly changing, especially in relation to gender, so the gender boundary for consultant gynaecologists was more apparent in 1953, whereas in 1993 the boundary for smoking category is stronger. Our responses to each category have changed over time.

We know that women in the developed world with devalued social roles-the unemployed, divorced, and women in full-time housework and child care-are more likely to smoke. This phenomenon may also be true of men in deprived circumstances. It follows then that if it is social role which impacts on smoking behaviour, then access to work, housing, transport, and child care may be the best public health measures we can provide for the developed world. This point is strongly made in the recent World Health Organisation publication, Women and Tobacco.

It is easy to imagine, watching trends in smoking prevalence in the developed world, that we are faced with the appalling prospect of having to sit and watch the rise of smoking prevalence in women in the developing countries of the world. There appears to be a shared notion between public health professionals and the tobacco industry that social evolution of developing countries will inexorably follow the westernisation route, and thereby lead to escalating smoking prevalence among women and decreasing smoking prevalence among men. We truly face the global prospect of more women taking up cigarette smoking than men within our lifetimes. In the developed world this will happen within only a few years, if present trends continue. ${ }^{11}$

I have heard environmentalists ask: Who are we to tell the developing world not to have the same aspirations as ourselves for material wealth, not to use energy and resources in order to fulfil those aspirations? It is these same aspirations which are currently being exploited by the trans-national tobacco companies to promote and sell their lethal products to women who aspire to the western ideal of equality with men.

This analysis by Clarke and colleagues will help us to consider more carefully the approach which communitywide smoking cessation and prevention programmes should take. The extent to which these programmes are effective for women, and affect women, will depend upon whether the programme designers decide to take account of women's ability to use cigarettes as controllers of their perceived social role.

Department of Psychology,

LIZ BATTEN

\section{University of Southampton, Southampton SO9 5NH,} $U K$

Liz Batten is a member of the ASH Working Group on Women and Smoking and the International Network of Women Against Tobacco. Her work on gender and smoking has been funded by the Cancer Research Campaign (UK).

1 Tomkins S. A modified model of smoking behaviour. In: Borgatta EF, Evans RR, eds, Smoking, Health and Behavior, Chicago: Aldine Publishing Co, 1968.

2 US Department of Health and Human Services. The health benefits of smoking cessation: a report of the Surgeon General, 1990. Atlanta, Georgia: Centers for Disease Control, Office on Smoking and Health, 1990. DHHS publication no (CDC) 90-8416.

3 Marsh A, Matheson J. Smoking attitudes and behaviour. Office of Population Censuses and Surveys. London: HMSO, 1983.

Grunberg NE, Winders SE, Wewers ME. Gender differences in tobacco use, Health Psychol 1991; 10 (2) 143-53.

5 Greaves L. The psychosocial determinants of women's tobacco use: How do women feel about smoking and how do societies benefit? Proceedings of we First Internation Northern Ireland in 1992, ISBN 09520222303.

6 Waldron I. Patterns and causes of gender differences in smoking. Soc Sci Med 1991; 32 (9) 989-1005.

7 Graham H. Women and smoking in the United Kingdom: the implications for health promotion, Health Promotion 1988; 4: 371-82.

8 Her share of misfortune: women, smoking, and low income. An expert report of the ASH Working Group on Women and Smoking. London: ASH, 1993.

9 Batten L. Smoking motivations and cessation rates: an analysis of genderbased differences. In: Burns J, De Jong $M$, eds. Women in psychology: recent developments in Britain. Equal Opportunities Int 1986; 5 (3/4) $22-7$.

10 Wells J, Batten L. Women, smoking and coping. Health Educ 1990; 49 (2) $57-60$.

11 Chollat-Traquet C. Women and Tobacco. World Health Organisation, Geneva: 1992 